\title{
Non-prescribed use of psychoactive prescription drugs among drug-impaired drivers in Sweden
}

Micaela Tjäderborn, Anna K Jönsson, Tatiana Zverkova Sandstrom, Johan Ahlner and Staffan Hägg

\section{Linköping University Post Print}

\section{Tweet}

N.B.: When citing this work, cite the original article.

Original Publication:

Micaela Tjäderborn, Anna K Jönsson, Tatiana Zverkova Sandstrom, Johan Ahlner and Staffan Hägg, Non-prescribed use of psychoactive prescription drugs among drug-impaired drivers in Sweden, 2016, Drug And Alcohol Dependence, (161), 77-85. http://dx.doi.org/10.1016/j.drugalcdep.2016.01.031

Copyright: Elsevier

http://www.elsevier.com/

Postprint available at: Linköping University Electronic Press

http://urn.kb.se/resolve?urn=urn:nbn:se:liu:diva-127559 


\section{Non-prescribed use of psychoactive prescription drugs among drug-impaired drivers in Sweden}

Micaela Tjäderborn ${ }^{1}$, Anna K Jönsson ${ }^{1,2}$, Tatiana Zverkova Sandström³, Johan Ahlner ${ }^{1,2}$, Staffan Hägg ${ }^{1,4}$

${ }^{1}$ Division of Drug Research/Clinical Pharmacology, Department of Medical and Health Sciences, Linköping University, Linköping, Sweden

${ }^{2}$ Department of Forensic Genetics and Forensic Toxicology, National Board of Forensic Medicine, Linköping, Sweden

${ }^{3}$ Institute of Medicine, Department of Molecular and Clinical Medicine, Sahlgrenska Academy, University of Gothenburg, Gothenburg, Sweden

${ }^{5}$ Futurum, Academy for Health and Care, Region Jönköping County, Jönköping, Sweden

Corresponding author:

Micaela Tjäderborn

Clinical Pharmacology, Division of Drug Research

Department of Medical and Health Sciences

Linköping University

S-581 83 Linköping

Sweden

micaela.tjaderborn@liu.se

Running head: Psychoactive prescription drugs and drug-impaired driving

Declarations of competing interests: The Authors taking part in this study declare that they have nothing to disclose regarding conflicts of interest with respect to this manuscript. MT has received financial support for this study from the County Council of Östergötland, Sweden (LIO-131751), the Forensic Science Centre, Sweden (CFV 121218) and Linköping University, Sweden (LIU 2009-01356). 


\section{Word count: $\underline{4195}$}

Key words: Prescription drug diversion, Non-prescribed use, Drug-impaired driving, Drug dispensing, Pharmacoepidemiology 


\section{Abstract}

Aims: To determine the prevalence of non-prescribed drug use among subjects suspected of drug-impaired driving with a confirmed intake of a psychoactive prescription drug, and to identify associated factors.

Methods: Subjects investigated for drug-impaired driving in Sweden during 2006-2009 with a confirmed intake of diazepam, flunitrazepam, tramadol, zolpidem or zopiclone were identified using the Swedish Forensic Toxicology Database. Information on dispensed prescription drugs was retrieved from the Swedish Prescribed Drug Register. Non-prescribed use was defined as_a confirmed use of a-psychoactive prescription drug intake confirmed by toxicological analysis in a subject by whom it was not dispensed in the 12 months preceding the sampling. Prevalence proportions were calculated for each drug and logistic regression was used to identify associated factors. Results: In total, 2225 subjects were included. The median age (range) was 34 (15-80) years and 1864 (83.8\%) subjects were male. Non-prescribed use was found in 1513 subjects (58.7\%); for flunitrazepam 103 (76.3\%), diazepam 1098 (74.1\%), tramadol 192 (40.3\%), zopiclone 60 (29.7\%), and zolpidem 60 (21.2\%) subjects, respectively. Younger age and multiple-substance use were associated with nonprescribed use, whereas ongoing treatment with other psychoactive drugs was negatively associated with nonprescribed use. Conclusions: Non-prescribed use of psychoactive prescription drugs was common in subjects suspected of drug-impaired driving and was more frequent for benzodiazepines and tramadol compared to zolpidem and zopiclone. The young and multi-substance users were more likely, whereas subjects with ongoing prescribed treatment with other psychoactive drugs were less likely, to use non-prescribed drugs.

Key words: Prescription drug diversion, Non-prescribed use, Drug-impaired driving, Drug dispensing, Pharmacoepidemiology 


\section{Introduction}

Psychoactive drugs are widely used in the treatment of common medical conditions such as pain, anxiety and sleep disorders (World Health Organization (WHO), 2006), but are also associated with substance use disorders and drug diversion (Casati et al., 2012; Fischer and Rehm, 2007; Griffiths et al., 2014; United Nations (UN), 2014; WHO, 2006). Drug diversion involves the illegal and medically unintended or unauthorized use and/or distribution of prescription drugs (Centers for Medicare \& Medicaid Services (CMS)CMMS, 2012). Opioid analgesics, benzodiazepines and benzodiazepine-like hypnotics are among the drug classes most frequently diverted (Fischer et al., 2014; Griffiths et al., 2014; UN, 2014; WHO, 2006). Prescription drug abuse and diversion is associated with serious medical, social and other short- and long-term consequences (Hall et al., 2008; Häkkinen et al., 2014; Rudisill et al., 2014; Rönkä et al, 2015; Zamparutti et al., 2011) and is a recognized global public health concern (WHO, 2006; UN, 2014; Griffiths et al., 2014)). Still, established, effective methods that evaluate their occurrence are missing (Secora et al., 2014).

Psychoactive prescription drugs are commonly and increasingly identified in the blood and urine samples of drug-impaired drivers (Bezemer et al., 2014; Burch et al., 2013; Christophersen and Mørland, 2008; Jones et al., 2009; Karjalainen et al., 2015; NBFM, 2014; Wilson et al., 2014). Because psychoactive drugs may impair driving ability, their users are at increased risk of traffic accidents (Dassanayake et al., 2011; Gustavsen et al., 2008; Hetland and Carr, 2014). Moreover, mental health problems as well as substance use disorders are more common (Freeman et al., 2011; Karjalainen et al., 2012; Lapham et al., 2001) and psychoactive drugs are more commonly prescribed (Karjalainen et al., 2015) among drug-impaired drivers than in the general population. Thus, investigations of drug-impaired driving are primarily conducted in individuals with a history of substance use problems.

The prevalence of psychoactive prescription drug diversion and the extent to which prescribed vs. nonprescribed drugs are involved, is largely unknown. It is well known that diversion of psychoactive prescription drugs involves original as well as falsified products and that diverted drugs have diverse origins, including personal prescriptions, drug theft, illegal Internet shopping as well as smuggling (Fischer et al., 2010; Fittler et al., 2013; Fountain et al., 2000; Inciardi et al., 2007; Lapyere-Mestre et al., 2014; Peirce et al., 2012; UN, 2014). Little is also known about the factors associated with diversion of psychoactive prescription drugs, although the established risk factors for substance use disorders, including young age (Hall et al., 2008; Rönkä et al., 2015), mental health problems and previous treatment with psychoactive drugs (Buurma et al., 2008, Cepeda et al., 2012, Bodén et al., 2014) are likely to be important. As opposed to other substance use disorders, however, prescription drug abuse has reported as equal in both sexes (Cepeda et al., 2012; Hall et al., 2008; Han et al., 2014; Rönkä et al., 2015) or greater in women (Buurma et al., 2008; Worley and Thomas, 2014). Finally, although it is well known that different psychoactive prescription drugs are diverted to different degrees (UN 1971, 1975, 2004-and 2014; WHO 2006), published comparative research is sparse. Previous studies have primarily investigated psychoactive prescription drugs as a group (Hall et al., 2008; Rönkä el al., 
2015), or focused on a separate drug class, such as opioids (Fischer et al., 2014; Häkkinen et al., 2014; Paulozzi et al., 2009; Wikner et al., 2014).

The confirmed intakeuse of a psychoactive prescription drug in an individual for whom it was prescribed would be expected, whereas in a subject without such prescribed treatment could indicate drug diversion. The aim of this study was to determine the prevalence of non-prescribed use for five psychoactive prescription drugs with different degrees of previously documented abuse potential (diazepam, flunitrazepam, tramadol, zolpidem and zopiclone) among subjects suspected of drug-impaired driving, and to identify associated factors. 


\section{Material and methods}

\subsection{Drug-impaired driving in Sweden}

Since 1999 Sweden has had a zero tolerance law for driving under the influence of scheduled psychoactive prescription drugs. Driving under the influence of such drugs that are used without a prescription, or in contravention of the prescribed instructions or product recommendations, is a crime (Jones, 2005). When an individual is suspected of driving under the influence of drugs (DUID), on account of a traffic accident, inappropriate driving behavior, DUID history or a known history of abuse, and at random stop-checks, the Swedish police is authorized to perform a field breath test and collect a blood sample from the driver. A positive blood sample is required to prosecute a driver suspected of DUID. Samples are sent to a national accredited laboratory at the National Board of Forensic Medicine in Linköping where the toxicological analyses are performed according to accredited standardized screening and verification procedures to determine the presence and concentrations of alcohol and illicit as well as prescription drugs that may affect driving ability (Jones, 2005; Ahlner et al., 2014). These include amphetamines, cannabis, ecstasy, opioids (opiates as well as synthetic and semi-synthetic opioids), cocaine and benzodiazepines, although the verification analyses depends on the specific substance or substances present at screening (i.e. if alcohol is identified at the field breath test or an illicit drug is identified upon screening, prescription drugs may not be further determined). Since 1992, the results of all forensic toxicology investigations are registered in a national database, ToxBase. In Sweden, all citizens receive a unique personal identification (ID), number which is included in national registers held by authorities to enable individual-based research and register-linkage.

\subsection{Study population}

The study population was identified in the Swedish national forensic toxicology database, ToxBase (National Board of Forensic Medicine, Sweden), and comprised Swedish citizens who were investigated for suspected DUID in Sweden between 1/7/2006 and 30/6/2009 and for whom toxicology analysis of blood confirmed intake of any of the following five drugs (and their Anatomical Therapeutic Classification (ATC) codes (WHO, 2008)): the benzodiazepinespsychoactive prescription drugs-diazepam (N05BA01) and flunitrazepam (N05CD03), the opioid analgesic tramadol (N02AX02) or the benzodiazepine-like hypnotics zopiclone (N05CF01) and zolpidem (N05CF02), defined by their Anatomical Therapeutic Classification (ATC) codes N05BA01, N05CD03, N02AX02, N05CF01 and N05CF02, respectively (WHO, 2008). These drugs were selected because of their different degrees of previously documented abuse potential (Medical Products Agency (MPA), 2009), and because of their relevance in the Swedish and international drug scene as well as in the forensic DUID population (Ahlner et al., 2014) at the time for the study. The Swedish classification of drugs corresponds

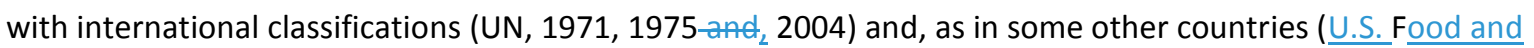
Drug Administration (FDA), 1970; U.K. Parliament, 1971), the Swedish classification comprises some additional drugs. Thus, the study drugs are scheduled in Sweden as class II (flunitrazepam), class III (tramadol), class IV 
(diazepam and zolpidem) and class V (zopiclone) narcotic drugs, involving restrictions in prescribing, dispensing, import, disposal and distribution of these drugs.

\subsection{Data collection}

This epidemiological study utilized information on toxicology results, dispensed prescription drugs, socioeconomy and registered residency from four national registers. For each driver the date of the first DUID investigation in the inclusion period was identified as the index date. When the intake of more than one of the study drugs was confirmed in a driver, an index date was set for each identified drug. Information from the National Forensic Toxicology database (ToxBase) comprising subject data (age at index, sex, personal identification number, previous DUID offences the five years preceding the investigation) and toxicological analysis results (identified drugs and their concentrations, and alcohol) were included, as well as some administrative data. Information on prescription drugs dispensed during the 12 month period preceding the index date (dispense date and drug substance by ATC level 5 (WHO, 2008)) was obtained from the Swedish Prescribed Drug Register (SPDR, National Board of Health and Welfare (Wettermark et al., 2007)). This register covers reimbursed and non-reimbursed outpatient dispensing of prescribed medicines in Sweden and includes personal identifiers. The Swedish LISA database (Longitudinal Integration Database for studies of health insurance and labour market, Statistics Sweden) was used to collect socioeconomic data (highest attained educational level, marital status, individual disposable income and individual country of birth) for the half calendar-year of the index date. Low, middle and high income levels were defined as the 25, 25-75 and 75 percentiles for the Swedish general population $>15$ years in the year 2008 as follows: 25\%: 107.436 SEK, 2575\%: 107.437-303.958 SEK, 75\%: 303.959 SEK, where 1 SEK= $€ 0.107$ (Statistics Sweden, 2015). The Swedish Geography database (Statistics Sweden) was used to collect information on national geographic registration of the subjects, also on a half-yearly basis. Data from the respective registers were linked individually using the personal ID number. Data compilation was performed at Statistics Sweden, including replacement of the personal ID number by a serial number to enable individual-level linkage of the data. This study was approved by the Regional Ethics Committee in Linköping, Sweden (M194-09).

\subsection{Statistical analysis}

Non-prescribed use of the psychoactive prescription drug identified in blood at forensic toxicology analysis was the outcome variable in this study. This was defined as-confirmed use a confirmed intake of the psychoactive prescription drug in a subject by whom the drug (by ATC code level 5) was not dispensed in the 12 months preceding the DUID arrest and toxicology sampling (index date). Thus, as opposed to classical drug utilization studies (Hallas, 2005), drug exposure in our study was determined using toxicology analysis results, where the detection of a certain drug upon toxicology analysis of blood confirmed its use (i.e. an intake of the drug). Whether this drug use was prescribed or not was further determined using drug dispensing data, where a dispense during the past 12 months was considered a marker of ongoing prescribed treatment. The 12-month 
cut-off was chosen taking various aspects into account, including the 1-year prescription validity time in Sweden, the Swedish drug reimbursement system allowing dispenses for a maximum of three months expenditure as well as the incidence rates (Hallas, 2005), prolonged waiting time periods (Pottegård and Hallas, 2013) and stock-piling of drugs used intermittently, but was also limited by the data available, particularly the lack of historical dispensing data before July 2005. A sensitivity analysis was conducted in which the 12 month cut-off was compared to 6 months. The prevalence proportion of non-prescribed use was calculated for each drug.

Descriptive statistics were used to characterize the population. The adjusted association between the exposure variables and non-prescribed use was assessed using separate logistic regression models, one for each drug. In a first step, all covariates yielding a $p$-value of $\leq 0.25$ in the global likelihood ratio test were included. In the subsequent final regression model covariates with $p$-values $\geq 0.05$ were excluded and $p$-values $<0.05$ and $95 \%$ confidence intervals (Cls) considered statistically significant. Forced inclusion of age and sex was applied in both steps. In the first step the following variables were included in the models: age, sex, highest attained educational level, marital status, individual income, country of birth, residency (living in a large city region or not), toxicology analysis results (including blood concentrations of the drug, and the presence in blood of other identified prescription drugs, illicit drugs and alcohol). Drug concentrations were assessed in relation to their therapeutic intervals based on the recommendations of the International Association of Forensic Toxicologists (TIAFT, 2010). Data management and statistical analyses were performed in SAS version 9.3 (SAS Institute, Cary, NC).

\section{Results}

The final study population included 2225 subjects with a toxicology analysis confirminged drug intake as follows: diazepam 1482 (65.6\%), tramadol 476 (21.1\%), zolpidem 283 (12.5\%), zopiclone 202 (9.8\%) and/or flunitrazepam 135 (6.0\%). There were 2578 DUID investigations of these subjects during the study period. The median age (and range) was 34 (15-80) years and 1864 (83.8\%) were male. Of these, $624(24.2 \%)$ had a confirmed intake of more than one of the five drug substances.

\subsection{Study population characteristics}

Characteristics of the study population are presented in Table 11. Most subjects were male, young, lived alone, in a large city region, were born in Sweden and had a low income level. The median age was higher, more were female, fewer had been taking an illicit drug and fewer had a history of DUID, of subjects identified with zolpidem or zopiclone compared to the other groups. A majority had a recently prescribed treatment with other prescription drugs, including those acting on the central nervous system (ATC N). Subjects using zolpidem and zopiclone more often were on a prescribed treatment with any other drug. 


\subsection{Prevalence of non-prescribed use}

In the total population of drivers, 1513 (58.7\%) subjects were non-prescribed users of the identified psychoactive prescription drug. The corresponding figures for each individual drug were as follows: flunitrazepam 103 (76.3\%), diazepam 1098 (74.1\%), tramadol 192 (40.3\%), zopiclone 60(29.7\%) and zolpidem $60(21.2 \%)$ and are shown in Figure 1. These proportions did not differ significantly when using the 6 month cut-off $(p>0.1)$.

\subsection{Factors associated with non-prescribed use}

The logistic regression models showed that, for all drugs but zopiclone, being aged 15-24 years compared to all other age groups was significantly associated with non-prescribed psychoactive prescription drug use, with the decreasing association with each successive age group. Sex did not significantly affect the likelihood of nonprescribed use. The importance of other variables differed between the psychoactive drugs studied. The results of the five regression models are presented by identified drug in Table $\underline{2} H$.

\section{Discussion}

\subsection{Main findings and their interpretation}

We found that most drug-impaired drivers in whom toxicology analysis confirmed the intake oftaking diazepam, flunitrazepam, tramadol, zolpidem or zopiclone, were using the drug without an identifiable ongoing prescribed treatment with the drug. The prevalence of this non-prescribed use varied for the different drugs from $21 \%$ for zolpidem to $76 \%$ for flunitrazepam, and non-prescribed use was found more often in the youngest age group. A toxicology result confirming the intake of multiple substances or of combinations of scheduled prescription drugs was associated with non-prescribed use, whereas subjects having at least one other recently dispensed medication_(including other psychoactive or scheduled drugs) were less likely to use non-prescribed drugs. Sex, income, educational level, marital status, residency or country of birth did not affect the likelihood of non-prescribed use.

In our study, the overall prevalence of non-prescribed use was 59\%. Previous studies have reported corresponding figures of that in the year before death, a personal prescription was missing in $63 \%$ (Hall et al., 2008) and 76\% (Rönkä et al., 2015)-of fataloverdoses with psychoactive prescription drugs. The slightly lower prevalence in our study may be explained by differences in the study population characteristics (fatally intoxicated vs. living subjects) and in the terminology between the studies. Rönkä et al. (2015) included also dispenses of other drugs in the same class (i.e. of opioid analgesics if tramadol was identified). Moreover, differences between countries with regard to legislation, prescription patterns, DUID investigations and other 
factors could explain differences between studies. In Sweden, many psychoactive prescription drugs are scheduled (MPA, 2009), programs to restrict the prescribing of e.g. benzodiazepines and opioids have been effective (NBHW, 2014), and the use of electronic health records allow for some control of drug prescribing and dispensing (Lapeyre-Mestre et al., 2014). However, psychoactive prescription drugs, including benzodiazepines, tramadol, zolpidem and zopiclone, are increasingly being smuggled into the country (SBA, 2014), a trend observed worldwide (UN, 2014).

The specific prescription drug taken was the major determinant of non-prescribed use in our study. We included five drugs with different degrees of previously documented abuse potential. Previous studies have not compared different psychoactive drugs in this respect (Hall et al., 2008; Karjalainen et al., 2015; Rönkä et al., 2014). In our study, $76 \%$ and $74 \%$ of subjects using flunitrazepam and diazepam, respectively, had no ongoing prescribed treatment with the identified drug, probably reflecting the high availability on the illegal market and low prescription rates of benzodiazepines (Lapeyre-Mestre et al., 2014; Simmons and Cupp, 1998; Toblin et al., 2010). Of subjects using tramadol, $40 \%$ had no ongoing prescribed treatment with the drug. The clinical utilization of tramadol and other opioid analgesics has increased markedly (Fischer et al., 2007; National Board of Health and Welfare, 2014; WHO, 2006; UN, 2014) and the diversion of tramadol has been debated (Tjäderborn et al., 2007, Winstock et al., 2014). In Sweden, in addition to the benzodiazepines, tramadol is one of the most commonly confiscated prescription drugs (Swedish Border Authority, 2014) and, as in some other countries, the drug is scheduled (MPA, 2007-and_2012). This study suggests that nonprescribed use of tramadol is less common than that of benzodiazepines, but is more frequent than for zolpidem and zopiclone. Of drivers with a confirmed intake of using zopiclone and zolpidem, 30\% and 21\%, respectively, were using these drugs without a prescription. Both drugs are recognized as having a lower abuse potential compared to the benzodiazepines (UN, 2004-and ${ }_{L} 2014$; WHO 2006). Notably, the high prescription rate of these hypnotics has been identified as an important clinical and public health problem (Bertisch et al., 2014; Moloney_et al., 2011; Neutel et al., 2012). High availability and convenience may be major reasons among prescription drug abusers for using medicines rather than illicit drugs (Inciardi et al., 2009). This study suggests that non-prescribed use is most common for the benzodiazepines and least common for the benzodiazepine-like hypnotics. All in all, whether drug-impaired drivers use psychoactive prescription drugs without a prescription appear to be linked to the abuse potential of the drug, where factors such as local legislation and prescription rates may be important in determining the drug availability in health care vs. the illegal market.

Being young compared to all older age groups was strongly associated with non-prescribed use in our study. Overall, the drivers were more often young and more were male compared to the expected population of patients with chronic pain, steep disorders or anxiety (Global Burden of Disease Study, 2013). Despite their young age, many drivers in our study had a history of previous DUID investigations: an indication in itself of problematic drug use. This is consistent with previous research showing that dDrug diversion (Buurma et al., 2008; Hall et al., 2008; Rönkä et al., 2015), substance use disorders (Compton et al., 2007), risk-taking behaviour, traffic accidents (Turner and McClure, 2003) and drug-impaired driving (Jones, 2005) are all more 
common in the young. A higher utilization of prescription drugs from illegal sources, including the Internet, and a more restrictive prescribing of psychoactive drugs in the young, may further contribute to the effect of age in our studyexplain our results.

In our study many subjects were using multiple substances as well as types of substances (illicit drugs and alcohol) that are indicative of substance use disorder. Subjects using diazepam and tramadol without a prescription had significantly more substances identified in their blood. For diazepam, zolpidem and zopiclone the presence of another scheduled prescription drug in blood significantly increased the likelihood of nonprescribed use. In recent years there has been a trend towards multiple-substance use among drug addicts (Darke, 2003; Jones et al., 2012) where several drugs are taken simultaneously to modify their individual effects. Other toxicological indicators of diversion, including high drug concentrations and the use of alcohol or illicit drugs, did not differ between subjects using prescribed from those using non-prescribed drugs.

The recent dispensing of other prescription drugs (particularly other psychoactive and scheduled drugs), predicted a prescribed drug use among drug-impaired drivers in our study. Conflicting findings have been reported by others (Bodén et al., 2014, Buurma et al., 2008; Cepeda et al., 2012, Peirce et al., 2012). There is a high psychiatric co-morbidity in subjects with substance use disorders, involving anxiety, depression, insomnia and autism-spectrum disorders (Compton et al., 2007; Degenhardt et al., 2001; Melartin et al., 2002) so their use of prescribed psychoactive drugs is expected. Our results might suggest that the recent dispensing of other prescribed drugs is a marker not only of medical history but also of having recently prescribed treatments with other drugs could be a marker of established health care contacts, and a higher probability of being prescribed psychoactive drugs.

Our study suggests that non-prescribed use of psychoactive prescription drugs occurs without gender differences and that neither income, educational level, marital status, country of birth or living in a large city region are associated with non-prescribed use. Although substance use disorders, risk taking behaviour (Sunderland et al., 2014; Turner et al., 2003) and drug-impaired driving (Jones, 2005) are more common in men, our and some other studies found no gender differences in prescription drug diversion (Han et al., 2014; Hall et al., 2008; Rönkä et al., 2014) whereas yet others reported a higher prevalence in women (Buurma et al., 2008). Gender differences in the methods of diversion may explain the results in our and other studies (Buurma et al., 2008). The socioeconomically disadvantaged are well known as a risk group of substance use disorders (Lee et al., 2013; Sutherland and Shepherd, 2001) but our results may be influenced by their higher disease prevalence and by socioeconomic differences in drug prescription rates. Overall, the majority of drivers had a low educational level, a low level of income and were living alone. Demographic differences between the drug use populations included an older age, more women and higher socioeconomic status of persons identified with the hypnotics and tramadol compared to subjects taking benzodiazepines. Most subjects in our study lived in the region of a large city, which we consideredWe considered living in the region of a large city as a factor possibly affecting illegal drug market and health care availability availability to the illegal drug market and to health care (including pharmacies) as well as determining traffic police density, but 
our results suggest that drug diversion is as common in rural as in urban areas, in line with some studies (Wang et al., 2014) but not with others (Monnat and Rigg, 2015). Altogether, our study suggests that non-prescribed use of psychoactive prescription drugs is related to some factors typical of substance use disorders, but not to some others, indicating, as some other studies (Agrawal et al., 2006; Karjalainen et al., 2011; Rigg and Monnat, 2015; Wu et al., 2015), that prescription drug misusers may differ from illicit drug users.

Early identification of diversion of psychoactive prescription drugs in the general population is important but established, effective methods are lacking. This study indicates thatmonitoring non prescribed use among drug-impaired drivers could be valuable. Moreover, the study highlights the importance of limiting prescription of these psychoactive prescription drugs, especially in the young and in subjects with a history of substance use disorder. Finally, our data support the suggestion by others (Karjalainen et al., 2015) that the DUID arrest could be used to identify subjects with non-prescribed use of psychoactive prescription drugs, enabling early individual-based interventions aimed at preventing adverse consequences later in life.

\subsection{Methodological considerations}

This was a nation-wide register-based study in which individual-level forensic data from toxicology analyses that confirmed drug intake were linked to data on recently prescribed drug treatments, enabling us to separate prescribed from non-prescribed drug use. Because psychoactive prescription drugs are commonly detected and substance use disorders are prevalent, the DUID population is relevant and useful in studies of utilization and diversion of psychoactive prescription drugs. Nonetheless, drug impaired drivers are a highly selected and heterogeneous population neither characteristic nor representative of patients with chronic pain, sleep disorders or anxiety (Global Burden of Disease Study, 2013). The study should be interpreted within these limitations.

We defined our outcome measure, non-prescribed use, as the confirmed intakeuse of the-a psychoactive prescription drug in a subject by whom the drug was not dispensed in the 12 months preceding the DUID arrest. This was considered an indicator of no ongoing prescribed treatment with the drug, and of drug diversion. The 12-month cut-off was applied taking into account the 1-year prescription validity time in Sweden, the Swedish drug reimbursement system which allows refills covering a maximum of three months expenditure, and considering the high intermittent use of the studied drugs, meaning long time intervals between dispenses, stock-piling of dispensed drugs and a prolonged waiting time period (WTD) (Hallas 2005; Pottegård and Hallas 2013). In our study, the average time between the DUID and last dispense of the identified drug was 4-11 days for the five drugs and $90 \%$ of the drivers redeemed their last prescription within less than 2-5 months before the arrest (data not shown). Also, there was no significant difference between the 6-month and 12-month cut-off limits. In our view, this confirms the stability of our cut-off limit in terms of assessing non-prescribed use in our population of drug-impaired drivers. Nonetheless, a sensitivity analysis including a longer observation period of 18-24 months, to confirm this, would have been valuable but was not 
possible due to limitations in the data. All in all, having a prescription older than one year, having a drug prescribed abroad or having received the drug when hospitalized, circumstances which would lead to the false assignment of non-prescribed users, were considered exceptional and unlikely to affect the overall results. limitations in historical data before July 2005 in the prescription register taking the Swedish drug reimbursement system into account, which allows refills for drugs covering a maximum of three months. Moreover, because adherence to prescribed drug treatment is low (Andersson et al., 2005)-and irregular administration of these drugs is common we choose a liberal limit of 12 months, and there were no significant differences when compared to a 6 month cut-off limit. Circumstances which could imply a medical intention of drug intake in the absence of a recent dispense (i.e. a false positive finding) include having a prescription older than one vear, having a drug prescribed abroad or having received the drug when hospitalized, but these were considered exceptional and unlikely to affect the overall results.

Intentions of the drug intake are an important aspect of substance use disorders and of drug diversion. However, this study does not enable to separate medical from non-medical intent, but only prescribed from non-precribed use. Medical prescriptions are a well known source of diverted drugs (Buurma et al., 2008; Peirce et al., 2012; Cepeda et al., 2012; Han et al., 2014; Nordmann et al., 2013) and thus personally prescribed use is not necessarily equivalent to medical intent. An overview of the drug refill patterns in the subjects using prescribed drugs in our study showed deviating refill patterns, including daily doses that far exceeded clinical recommendations, in some subjects but not in others, indicating heterogeneity within this group. The degree, to which drivers were assigned in our study as having a prescribed treatment although their intentions were non-medical, remains unknown.

Police practices and routines at the forensic departments partly limited the toxicology analyses on which this study depends. Because of multi-substance use in this population there is overlap between the groups. For practical reasons the study was based on identified main compounds rather than their metabolites. Tramadol and flunitrazepam are, however, rapidly and extensively metabolized (Boxenbaum et al., 1978; Grond and Sablotzki, 2004)-and thus toxicological analysis of blood may detect a combination of the mother compound and metabolites, or only metabolites. Moreover, analyses for prescription drugs are not always conducted if alcohol or illicit drugs are detected. In addition, there is neither standardization nor information on the time interval between drug intake and blood sampling, nor is there information on the duration of treatment. Thus trough values and steady state concentrations are not available, rendering drug concentrations difficult to interpret. All in all, our study population encompasses those drivers who were screened for the studied drugs and where the main compound was present. Effects on the results due to inter-individual differences with regards to drug combinations, drug metabolism and other factors cannot be excluded. Higher-thantherapeutic concentrations were identified using the therapeutic intervals recommended by TIAFT (TIAFT, 2010). Difficulties related to determining therapeutic vs toxic blood concentrations of prescription drugs have been highlighted previously (Jönsson et al., 2014). 
As a non-controlled epidemiological study the results cannot be used to determine causality. Moreover, factors such as access to a car, drug abuse history, psychiatric history and traffic police density likely affect our outcome measure but could not be fully controlled for in our analysis. Finally, the present study used Swedish data for the years 2006-2009 for a selection of five drugs with high relevance to the Swedish drug abuse scene at the time for the study. The prevalence of non-prescribed use likely varies between countries and over time on account of legislation and prescription systems as well as trends in the illegal drug market and clinical utilization of medicines. Further studies of diversion of psychoactive prescription drugs, including more recent data of high international relevance, are therefore warranted.

Early identification of diversion of psychoactive prescription drugs in the population is important but established, effective methods are lacking. Our results indicate that monitoring non-prescribed use among drug-impaired drivers may be valuable.

\subsection{Conclusions}

Non-prescribed use of psychoactive prescription drugs was common among subjects suspected of drugimpaired driving and was more frequent in subjects using benzodiazepines and tramadol compared to subjects using zolpidem and zopiclone. The young and multi-substance users were more likely, whereas subjects with ongoing prescribed treatment with other psychoactive or scheduled prescription drugs were less likely to use non-prescribed drugs in our study. 


\section{References}

Agrawal A., Lynskey $_{L}$ M.T., Madden, P.A.F., Bucholz ${ }_{L}$ K.K., Heath A.C., 2006. A latent class analysis of illicit drug abuse/dependence: results from the National Epidemiological Survey on Alcohol and Related conditions.

Addiction. 102, 94-104.

Ahlner $_{L} J_{\text {., Holmgren }}$ A., Jones $_{L}$ A.W., 2014. Prevalence of alcohol and other drugs and the concentrations in blood of drivers killed in road traffic crashes in Sweden. Scand J. Publ. Health. 42(2),177-83.

http://dx.doi.org/10.1177/1403494813510792

Andersson K., Melander A., Svensson C., Lind O., Nilsson J.L., 2005. Repeat prescriptions: refill adherence in relation to patient and prescriber characteristics, reimbursement level and type of medication. Eur. J. Public Health. 15(6), 621-6.

Bertisch, S.M., Herzig, S.J., Winkelman, J.W., Buettner ${ }_{L}$ C., 2014. National use of prescription medications for insomnia: NHANES 1999-2010. Sleep. 37(2), 343-9. http://dx.doi.org/10.5665/sleep.3410

Bezemer ${ }_{L}$ K.D., Smink ${ }_{L}$ B.E., van Maanen, R., Verschraagen, M., de Gjer ${ }_{L}$ J.J., 2014. Prevalence of medicinal drugs in suspected impaired drivers and a comparison with the use in the general Dutch population. Forensic Sci. Int. 241. 203-11. http://dx.doi.org/10.1016/j.forsciint.2014.06.004

Bodén ${ }_{L}$ R., Wettermark ${ }_{L}$ B., Brandt, L., Kieler ${ }_{L} H_{\text {., }}$ 2014. Factors associated with pregabalin dispensing at higher than the approved maximum dose. Eur J Clin Pharmacol. 70(2), 197-204. http://dx.doi.org/10.1007/s00228013-1594-5

Boxenbaum, H.G., Posmanter ${ }_{L}$ H.N., Macasieb ${ }_{L}$ T., Geitner ${ }_{L}$ K.A., Weinfeld ${ }_{L}$ R.E., Morre J.D., Darragh ${ }_{L}$ A., O’Kelly ${ }_{2}$ D.A., Weissman, L., Kaplan, S.A., 1978. Pharmacokinetics of flunitrazepam following single- and multiple-dose oral administration to healthy human subjects. J. Pharmacokinet. Biopharm. 6(4), 283-93.

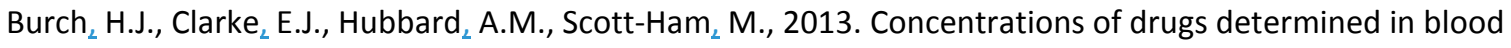
samples collected from suspected drugged drivers in England and Wales. J. For. Leg. Med. 20, 278-89. http://dx.doi.org/10.1016/j.jflm.2012.10.005

Buurma $_{L} H_{\text {., Bouvy }}$ M.L., De Smet B.A., Floor-Schreudering $_{L}$ A., Leufkens ${ }_{L}$ H.G., Egerts ${ }_{L}$ A.C., 2008. Prevalence and determinants of pharmacy shopping behavior. J. Clin. Pharm. Ther. 33(1), 17-23.

http://dx.doi.org/10.1111/j.1365-2710.2008.00878.x

Casati ${ }_{L}$ A., Sedefov ${ }_{L}$ R., Preffer-Gerschel ${ }_{L}$ T., 2012. Misuse of medicines in the European Union: a systematic review of the literature. Eur. Addict. Res. 18, 228-45. http://dx.doi.org/10.1159/000337028

Centers for Medicare \& Medicaid Services (CMS), 2012. Center for Program Integrity. Drug diversion in the Medicaid Program: State Strategies for Reducing Prescription Drug Diversion in Medicaid. Retrieved on 27 October 2015. http://www4a.cms.gov/MedicaidIntegrityProgram/Downloads/drugdiversion.pdf.

Cepeda, M.S., Fife, D., Chow ${ }_{L}$ W., Mastrogiovanni, G., Henderson, S.C., 2012. Assessing opioid shopping behavior: a large cohort study from a medication dispensing database in the US. Drug Saf. 35(4), 325-34. http://dx.doi.org/10.2165/11596600-000000000-00000

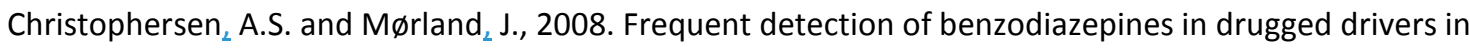
Norway. Traffic Inj. Prev. 9, 98-104. http://dx.doi.org/10.1080/15389580701869190

Compton, W.M., Thomas, Y.F., Stinson, F.S., Grant B.F., 2007. Prevalence, correlates, disability, and comorbidity of DSM-IV drug abuse and dependence in the United States: results from the national 
epidemiologic survey on alcohol and related conditions. Arch. Gen. Psychiatry. 64, 566-76.

http://dx.doi.org/10.1001/archpsyc.64.5.566

Darke $_{L}$ S., 2003. Polydrug use and overdose: overthrowing old myths. Addiction. 98(6), 711.

Dassanayake $_{L}$ T., Michie, P., Carter ${ }_{L}$ G., Jones ${ }_{L}$ A., 2011. Effects of benzodiazepines, antidepressants and opioids on driving: a systematic review and meta-analysis of epidemiological and experimental evidence. Drug Saf. 34, 125-156. http://dx.doi.org/10.2165/11539050-000000000-00000

Degenhardt, L., Hall L., Lynskey, M., 2001. Alcohol, cannabis and tobacco use among Australians: a comparison of their associations with other drug use and use disorders, affective and anxiety disorders, and psychosis. Addiction. 96, 1603-14. http://dx.doi.org/10.1046/j.1360-0443.2001.961116037.x

Fischer ${ }_{L}$ B., Rehm J., $_{2}$ 2007. Illicit opioid use in the $21^{\text {st }}$ centrury: witnessing a paradigm shift? Addiction. 102, 499-501.

Fischer ${ }_{L}$ B., Bibby ${ }_{L}$ M., Bouchard ${ }_{L}$ M., 2010. The global diversion of pharmaceutical drugs. Non-medical use and diversion of psychotropic prescription drugs in North America: a review of sourcing routes and control measures. Addiction. 105, 2062-70. doi: 10.1111/j.1360-0443.2010.03092.x.

http://dx.doi.org/10.1111/j.1360-0443.2010.03092.x

Fischer, B., Keates ${ }_{L}$ A., Bühringer ${ }_{L}$ G., Reimer ${ }_{L}$ J., Rehm ${ }_{L}$ J., 2014. Non-medical use of prescription opioids and prescription-opioid related harms: why so markedly higher in North America compared to the rest of the world? Addiction. 109, 177-81. http://dx.doi.org/10.1111/add.12224

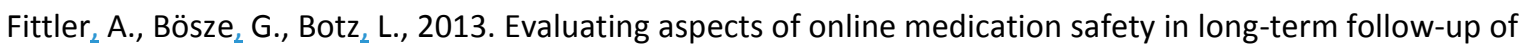
136 Internet pharmacies: illegal rouge online pharmacies flourish and are long-lived. J. Med. Internet. Res. 15(9), e199. http://dx.doi.org/10.2196/jmir.2606

Food and Drug Administration (FDA), 1970. Controlled Substances Act, Comprehensive Drug Abuse Prevention and Control Act, Public law no 91-513 84 Stat. 1242. The 91st United States Congress, 27 October 1970.

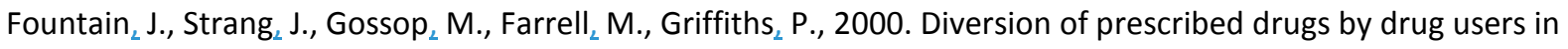
treatment: analysis of the UK market and new data from London. Addiction. 95(3), 393-406.

http://dx.doi.org/10.1046/j.1360-0443.2000.95339310.x

Freeman, J., Maxwell J.C., Davey J., 2011. Unraveling the complexity of driving while intoxicated: a study into the prevalence of psychiatric and substance abuse comorbidity. Accid. Anal. Prev. 43, 34-39.

http://dx.doi.org/10.1016/j.aap.2010.06.004

Global Burden of Disease Study 2013 Collaborators, 2015. Global, regional, and national incidence, prevalence, and years lived with disability for 301 acute and chronic diseases and injuries in 188 countries, 1990-2013: a systematic analysis for the Global Burden of Disease Study 2013. Lancet. 386(9995):743-800.

http://dx.doi.org/10.1016/S0140-6736(15)60692-4

Griffiths, P., Evans-Brown, M., Sedefov ${ }_{L}$ R., 2014. The (mis)use of psychoactive medicines: getting the balance right in complex systems. Addiction. 109, 182-3. Commentary on Fischer et al., 2014. Addiction. 109, 177-81. http://dx.doi.org/10.1111/add.12306

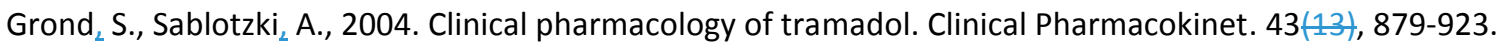
http://dx.doi.org/10.2165/00003088-200443130-00004 
Gustavsen, I., Bramness, J.G., Skurtveit S., Engeland $_{L}$ A., Neutel, I., Mørland J., $_{L}$ 2008. Road traffic accident risk related to prescriptions of the hypnotics zopiclone, zolpidem, flunitrazepam and nitrazepam. Sleep Medicine. 9, 818-22. http://dx.doi.org/10.1016/j.sleep.2007.11.011

Hall, A.J., Logan, J.E., Toblin, R.L., Kaplan, J.A., Kraner, J.C., Bixler, D., Crosby L A.E., Paulozzi, L.J., 2008. Patterns of abuse among unintentional pharmaceutical overdose fatalities. JAMA. 300(22), 2613-20.

http://dx.doi.org/10.1001/jama.2008.802

Hallas, J., 2005. Drug utilization statistics for individual-level pharmacy dispensing data. Pharmacoepidemiol

\section{Drug Saf. 14, 455-63. http://dx.doi.org/10.1002/pds.1063}

Han $_{L}$ H., Kass, P.H., Wilsey ${ }_{L}$ B.L., Li, C.S., 2014. Increasing trends in Schedule II opioid use and doctor shopping during 1999-2007 in California. Pharmacoepidemiol. Drug. Saf. 23(1), 26-35.

http://dx.doi.org/10.1002/pds.3496

Hetland $_{L}$ A. and Carr, D.B., 2014. Medications and impaired driving. Ann. Pharmacother. 48(4), 494-506. http://dx.doi.org/10.1177/1060028014520882

Häkkinen, M., Vuori, E., Ojanpera L I., 2014. Prescription opioid abuse based on representative postmortem toxicology. For. Sci. Int. 245, 121-25. http://dx.doi.org/10.1016/j.forsciint.2014.10.028

Inciardi ${ }_{L}$ J.A., Surratt ${ }_{L}$ H.L., Kurtz ${ }_{L}$ S.P., Cicero ${ }_{L}$ T.J., 2007. Mechanisms of prescription drug diversion among drug-involved club- and street-based populations. Pain Med. 8(2), 171-83. http://dx.doi.org/10.1111/j.15264637.2006.00255.x

Inciardi, J.A., Surratt, H.L., Cicero, T.J., Beard ${ }_{L}$ R.A., 2009. Prescription opioid abuse and diversion in an urban community: the results of an ultrarapid assessment. Pain Med. 10(3), 537-48.

http://dx.doi.org/10.1111/j.1526-4637.2009.00603.x

Jones, A.W., 2005. Driving under the influence of drugs in Sweden with zero concentration limits in blood for controlled substances. Traffic Inj. Prev. 6, 317-22. http://dx.doi.org/10.1080/15389580500253760

Jones $_{L}$ A.W., Kugelberg ${ }_{L}$ F.C., Holmgren, A., Ahlner, J., 2009. Five-year update on the occurrence of alcohol and other drugs in blood samples from drivers killed in road-traffic crashes in Sweden. For. Sci. Int. 186, 56-

62. http://dx.doi.org/10.1016/j.forsciint.2009.01.014

Jones ${ }_{L}$ J.D., Mogali, S., Comer, S.D., 2012. Polydrug abuse: a review of opioid and benzodiazepine combination use. Drug Alcohol. Depend. 125(1-2), 8-18. http://dx.doi.org/10.1016/j.drugalcdep.2012.07.004

Jönsson A.K., Söderberg C., Espnes K.A., Ahlner J., Eriksson A., Reis M., Druid H., 2014. Sedative and hypnotic drugs- fatal and non-fatal reference blood concentrations. For. Sci. Int. 236, 138-45. doi: 10.1016/j.forsciint.2014.01.005.

Karjalainen K., Lintonen $_{L}$ T., Impinen A., Lillsunde $_{L}$ P., Mäkelä, P., Rahkonen, O., Haukka J., Ostamo A., $_{2} 2011$. Socio-economic determinants of drugged driving- a register based study. Addiction. 106, 1448-1459. http://dx.doi.org/10.1111/j.1360-0443.2011.03422.x

Karjalainen, K., Lintonen ${ }_{L}$ T., Joukamaa ${ }_{L}$ M., Lillsunde $_{L}$ P., 2012. Mental disorders associated with driving under the influence of alcohol and/or drugs: a register-based study. Eur. Addict. Res. 19(3), 113-20.

http://dx.doi.org/10.1159/000342569 
Karjalainen, K., Haukka J., Lintonen $_{L}$ T., Joukamaa $_{L}$ M., Lillsunde $_{L}$ P., 2015. The use of psychoactive prescription drugs among DUI suspects. Drug Alc. Dep. 155, 215-221.

http://dx.doi.org/10.1016/j.drugalcdep.2015.07.1195

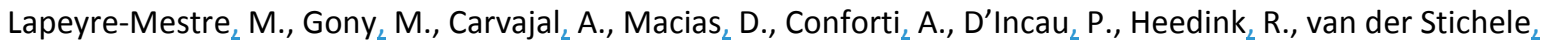
R., Bergman, U., 2014. A European community-based survey to investigate patterns of prescription fraud through identification of falsified prescriptions. Eur. Addict. Res. 20, 174-82.

http://dx.doi.org/10.1159/000356812

Lapham ${ }_{L}$ S.C., Smith E., C'De Baca $_{L}$ J., Chang I., Skipper $_{L}$ B.J., Baum ${ }_{L}$ G., Hunt ${ }_{L}$ W.C., 2001. Prevalence of psychiatric disorders among persons convicted of driving while impaired. Arch. Gen. Psychiatry. 58, 943-949. http://dx.doi.org/10.1001/archpsyc.58.10.943

Lee ${ }_{L}$ J.O., Herrenkohl L T.I., Kosterman, R., Small, C.M., Hawkins, J.D., 2013. Educational inequalities in the cooccurrence of mental health and substance use problems, and its adult socio-economic consequences: a longitudinal study of young adults in a community sample. Public Health. 127(8), 745-53.

http://dx.doi.org/10.1016/j.puhe.2013.04.005

Medical Products Agency (MPA), 2009. LVFS 1997:12 with adjustments until 2009:22 Swedish law on narcotic drugs. [Föreskrift om ändring i Läkemedelsverkets föreskrifter (LVFS 1997:12) om förteckningar över narkotika (LVFS 2009:22)]. Medical Products Agency $L_{L^{-}}$Sweden. 25 November 2009.

Medical Products Agency (MPA), 2012. Communication regarding changed legislation for tramadol. [Läkemedel med tramadol är narkotika]. Retrieved on 30 April 2012. https://lakemedelsverket.se/Allanyheter/NYHETER-2012/Lakemedel-med-tramadol-ar-narkotika/.

Melartin, T.K., Rytsälä, H.J., LeskeläL U.S., Lestelä-Mielonen, P.S., Sokero L T.P., Isometsä, E.T., 2002. Current comorbidity of psychiatric disorders among DSM-IV major depressive disorder patients in psychiatric care in the Vantaa Depresion Study. J. Clin. Psych. 63, 126-34.

Moloney, M.E., Konrad ${ }_{L}$ T.R., Zimmer ${ }_{L}$ C.R., 2011. The medicalization of sleeplessness: a public health concern. Am. J. Public Health. 101(8), 1429-33. http://dx.doi.org/10.2105/AJPH.2010.300014

Monnat S.M. and Rigg K.K., 2015. Examining rural/urban differences in prescription opioid misuse among US adolescents. J Rural Health. [Epub ahead of print] http://dx.doi.org/10.1111/jrh.12141

National Board of Forensic Medicine (NBFM), 2014. Internal unpublished data from the National Forensic Foxicology Register (ToxBase). Linköping, Sweden, October 2014.

National Board of Health and Welfare (NBHF), 2014. Yearly drug sales statistics [Socialstyrelsens databas för läkemedelsstatistik]. Retrieved on 11 September 2014.

http://www.socialstyrelsen.se/statistik/statistikdatabas/lakemedel.

Neutel ${ }_{L}$ C.I., Skurveit ${ }_{L}$ S., Berg ${ }_{L}$ C., 2012. What is the point of guidelines? Benzodiazepine and z-hypnotic use by an elderly population. Sleep Med. 13(7), 893-7. http://dx.doi.org/10.1016/j.sleep.2011.12.014

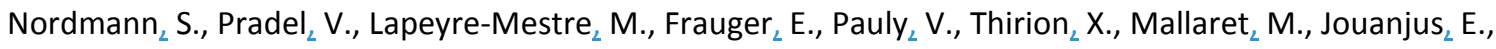

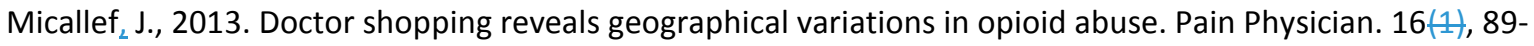
100.

Paulozzi L.J., Logan, J.E., Hall A.J., McKinstry, E., Kaplan, J.A., Crosby ${ }_{L}$ A.E., 2009. A comparison of drug overdose deaths involving methadone and other opioid analgesics in West Virginia. Addiction. 104(9), $1541-8$. http://dx.doi.org/10.1111/j.1360-0443.2009.02650.x 
Peirce $_{L}$ G.L., Smith M.J., Abate $_{L}$ M.A., Halverson, J., 2012. Doctor and pharmacy shopping for controlled substances. Med. Care. 50(6), 494-500. http://dx.doi.org/10.1097/MLR.0b013e31824ebd81

Pottegård, A. and Hallas, J., 2013. Assigning exposure duration to single prescriptions by use of the waiting time distribution. Pharmacoepidemiol Drug Saf. 22, 803-9. http://dx.doi.org/10.1002/pds.3459

Rigg $_{\perp}$ K.K. and Monnat, S.M., 2015. Comparing characteristics of prescription painkiller misusers and heroin users in the United States. Addict. Behav. 51, 106-12. [Epub ahead of print].

http://dx.doi.org/10.1016/j.addbeh.2015.07.013

Rudisill, T.M., Zhao, S., Abate ${ }_{L}$ M.A., Coben J.H., Zhu $_{L}$ M., 2014. Trends in drug use among drivers killed in U.S. traffic crashes, 1999-2010. Accid. Anal. Prev. 70, 178-87. http://dx.doi.org/10.1016/j.aap.2014.04.003

Rönkä, S., Karjalainen, K., Vuori, E., Mäkelä, P., 2015. Personally prescribed psychoactive drugs in overdose deaths among drug abusers: A retrospective register study. Drug and Alcohol Review. 34(1), 82-9.

http://dx.doi.org/10.1111/dar.12182

Secora, A.M., Dormitzer, C.M., Staffa, J.A., Dal Pan, G.J., 2014. Measures to quantify the abuse of prescription opioids: a review of data sources and metrics. Pharmacoepidemiol Drug Saf. 23, 1227-37. http://dx.doi.org/10.1002/pds.3711

Simmons, M.M. and Cupp ${ }_{L}$ M.J., 1998. Use and abuse of flunitrazepam. Ann. Pharmacother. 32(1), 117-9. http://dx.doi.org/10.1345/aph.17027

Statistics Sweden, 2015. Statistics on income distributions and income percentiles in Sweden for the year 2008. [Sammanräknad förvärvsinkomst för boende i Sverige >15 år för året 2008, Petter Lundberg]. 2015-1210. Örebro, Sweden.

Sunderland ${ }_{L}$ M., Slade ${ }_{L}$ T., Krueger ${ }_{L}$ R.F., 2015. Examining the shared and unique relationships among substance use and mental disorders. Psychol. Med. 45(5), 1103-13. http://dx.doi.org/10.1017/S0033291714002219

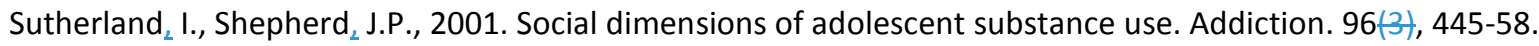
http://dx.doi.org/10.1046/j.1360-0443.2001.9634458.x

Swedish border authority (SBA), 2014. Annual statistics of the Swedish Border Authority and personal correspondence. [Nationell beslagsstatistik, helår]. Retrieved on 13 September 2014.

http://www.tullverket.se/press/beslagsstatistik/nationellbeslagsstatistik/helarnationellbeslagsstatistik.4.16f3e c5a144fd16b2f4262.html.

The International Association of Forensic Toxicologists (TIAFT), 2010. Reference Blood Level List of Therapeutic and Toxic Concentrations. Bulletin of TIAFT. 26(1), S1-34.

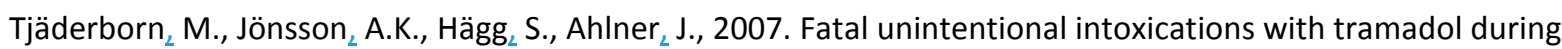
1995-2005. Forensic Sci. Int. 173(2 3), 107-11. http://dx.doi.org/10.1016/j.forsciint.2007.02.007

Toblin, R.L., Paulozzi L.J., Logan, E.J., Hall A.J., Kaplan, J.A., 2010. Mental illness and psychotropic drug use among prescription drug overdose deaths: a medical examiner chart review. J. Clin. Psychiatry. 71(4), 4916. http://dx.doi.org/10.4088/JCP.09m05567blu

Turner ${ }_{L} \mathrm{C}_{\text {., }} \mathrm{McCl}_{\mathrm{r}} \mathrm{L}_{L}$ R., 2003. Age and gender differences in risk-taking behavior as an explanation for high incidence of motor vehicle crashes as a driver in young males. Inj. Control Saf. Promot. 10(3), 123-30. http://dx.doi.org/10.1076/icsp.10.3.123.14560 
U_K. Parliament, 1971. Misuse of Drugs Act, c. 38, Parliament of the United Kingdom of Great Britain and Northern Ireland, 27 May 1971.

United Nations (UN), 1971. Convention on Psychotropic Substances. Vienna, 1 Januari-21 February 1971.

United Nations (UN), 1975. Single Convention on Narcotic Drugs of 1961, as amended by the protocol amending the Single Convention on Narcotic Drugs, 1961. Vol 976. New York, 8 August 1975.

United Nations (UN), 2004. International Narcotics Control Board Yellow List: List of narcotic drugs under international control. Vienna, Austria, December 2004.

United Nations (UN), 2014. Report of the International Narcotics Control Board for 2013. Vienna, Austria, 4 March 2014.

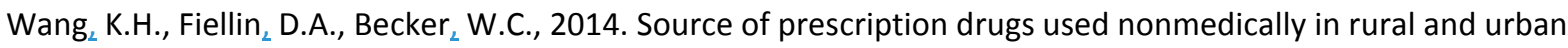
populations. Am. J. Drug Alcohol Abuse. 40(4), 292-303. http://dx.doi.org/10.3109/00952990.2014.907301

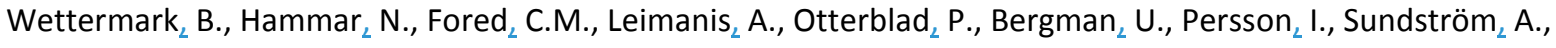
Westerholm B., Rosén, M., 2007. The new Swedish Prescribed Drug Register-Opportunities for pharmacoepidemiological research and experience from the first six months. Pharm. Drug. Saf. 16(7), 726-35. http://dx.doi.org/10.1002/pds.1294

Wikner, B.N., Öhman ${ }_{L}$ I., Seldén,$T$, Druid ${ }_{L} H$, Brandt, L, Kieler ${ }_{L} H_{\text {., }}$ 2014. Opioid-related mortality and filled prescriptions for buprenorphine and methadone. Drug Alcohol Rev. 33(5), 491-8.

http://dx.doi.org/10.1111/dar.12143

Wilson F.A., Stimpson J.P., Pagàn, J.A., 2014. Fatal crashes from drivers testing positive for drugs in the U.S. 1993-2010. Public Health Rep. 129(4), 342-50.

Winstock ${ }_{L}$ A.R., Borschmann ${ }_{L}$ R., Bell ${ }_{L}$ J., 2014. The non-medical use of tramadol in the UK: findings from a large community sample. Int. J. Clin. Pract. 68(9), 1147-51. http://dx.doi.org/10.1111/ijcp.12429

World Health Organization (WHO), 2006. Technical report of the WHO Expert Committee on Drug Dependence, WHO technical report series 942, 34:th report. Geneva, March 2006.

World Health Organization (WHO), 2008. Collaborating Centre for Drug Statistics Methodology, Guidelines for ATC classification and DDD assignment, 2009. Oslo, 2008.

Worley $_{L}$ J. and Thomas, S.P., 2014. Women who doctor shop for prescription drugs. West. J. Nurs. Res. 36(4), 456-74. http://dx.doi.org/10.1177/0193945913509692

$W_{L}$ L.T., Woody $y_{L}$ G.E., Yang C., Blazer $_{L}$ D.G., 2011. How do prescription users differ from users of heroin or other drugs in psychopathology: results from the National Epidemiology Survey on Alcohol and Related Conditions. J. Addict. Med. 5(1): 28-35. http://dx.doi.org/10.1097/ADM.0b013e3181e0364e

Zamparutti, G., Schifano, F., Corkey J.M., Oyefeso ${ }_{L}$ A., Ghodse ${ }_{L}$ A.H., 2011. Deaths of opiate/opioid misusers involving dihydrocodeine, UK, 1997-2007. Br. J. Clin. Pharmacol. 72, 330-7. http://dx.doi.org/10.1111/j.13652125.2011.03908.x 


\section{Figures and tables}

Table 1. Characteristics of subjects suspected of drug-impaired driving with a confirmed intake of a psychoactive prescription drug $(\mathrm{N}=2225)$

\begin{tabular}{|c|c|c|c|c|c|}
\hline \multirow[t]{2}{*}{ Variable } & Diazepam & Flunitrazepam & Tramadol & Zolpidem & Zopiclone \\
\hline & $\bar{N}=1482(65.6 \%)$ & $\mathrm{N}=135(6.0 \%)$ & $\mathrm{N}=476(21.1 \%)$ & $\mathrm{N}=283(12.5 \%)$ & $\mathrm{N}=202(9.8 \%)$ \\
\hline Age, years, median (range) & $32(15-73)$ & $33(16-62)$ & $33(15-75)$ & $43(18-80)$ & $41(17-71)$ \\
\hline $15-24$ years & $322(21.7)$ & $21(15.6)$ & $114(24.0)$ & $30(10.6)$ & $25(12.4)$ \\
\hline $25-34$ years & $508(34.3)$ & $56(41.5)$ & $145(30.5)$ & $53(18.7)$ & 39 (19.3) \\
\hline $35-44$ years & $364(24.6)$ & $38(28.2)$ & $126(26.5)$ & $71(25.1)$ & $62(30.7)$ \\
\hline $45-54$ years & $239(16.1)$ & $16(11.9)$ & $69(14.5)$ & $69(24.4)$ & $53(26.2)$ \\
\hline$\geq 55$ years & $49(3.3)$ & $4(3.0)$ & $22(4.6)$ & $60(21.2)$ & $23(11.4)$ \\
\hline Sex, male $n(\%)$ & $1296(87.5)$ & $110(81.5)$ & $400(84.0)$ & $195(68.9)$ & $138(68.3)$ \\
\hline \multicolumn{6}{|l|}{ Previous history of DUID* } \\
\hline Any previous investigation, $\mathrm{n}(\%)$ & $875(59.0)$ & $85(63.0)$ & $192(40.3)$ & $75(26.5)$ & $79(39.1)$ \\
\hline No of investigations, median(range) & $1(0-47)$ & $1(0-22)$ & $0(0-20)$ & $0(0-10)$ & $0(0-22)$ \\
\hline \multicolumn{6}{|l|}{ Education $\mathrm{n}(\%)^{* *}$} \\
\hline Primary school & $758(51.2)$ & $68(50.4)$ & $214(45.0)$ & $82(29.0)$ & $86(42.6)$ \\
\hline Secondary school & $594(40.1)$ & $51(37.8)$ & $213(44.8)$ & $142(50.2)$ & $80(39.6)$ \\
\hline University or College & $64(4.3)$ & $8(5.9)$ & $39(8.2)$ & $52(18.4)$ & $32(15.8)$ \\
\hline Missing & $66(4.5)$ & $8(5.9)$ & $10(2.1)$ & $7(2.5)$ & $4(2.0)$ \\
\hline \multicolumn{6}{|l|}{ Income, individual disposable, $\mathrm{n}(\%)^{* * *}$} \\
\hline Low income $(<25 \%)$ & $831(56.1)$ & $76(56.3)$ & $231(48.5)$ & $75(26.5)$ & $87(43.1)$ \\
\hline Mid income $(25-75 \%)$ & $531(35.8)$ & $48(35.6)$ & $197(41.4)$ & $144(50.9)$ & $87(43.1)$ \\
\hline High income (>75\%) & $89(6.0)$ & $6(4.4)$ & $46(9.7)$ & $61(21.6)$ & $27(13.4)$ \\
\hline \multicolumn{6}{|l|}{ Marital status, n (\%) } \\
\hline Married or cohabitant & $127(8.6)$ & $21(15.6)$ & $71(14.9)$ & $57(20.1)$ & $41(20.3)$ \\
\hline Unmarried, divorced, widow(er) & $1324(89.3)$ & $109(80.7)$ & $403(84.7)$ & $223(78.8)$ & $160(79.2)$ \\
\hline Missing & $31(2.1)$ & $5(3.7)$ & $2(0.4)$ & $3(1.1)$ & $1(0)$ \\
\hline \multicolumn{6}{|l|}{ Country of birth, $\mathrm{n}(\%)$} \\
\hline Sweden & $1260(85.0)$ & $105(77.8)$ & $378(79.4)$ & $244(86.2)$ & $166(82.2)$ \\
\hline Other Nordic countries & $78(5.3)$ & $2(1.5)$ & $17(3.6)$ & $8(2.8)$ & $13(6.4)$ \\
\hline Europe & $74(5.0)$ & $13(9.6)$ & $26(5.5)$ & $19(6.7)$ & $14(6.9)$ \\
\hline Outside Europe & $66(4.5)$ & $13(9.6)$ & $55(11.6)$ & $19(6.7)$ & $14(6.9)$ \\
\hline Living in the region of a large city, $\mathrm{n}(\%)$ & $669(45.1)$ & $75(55.6)$ & $229(48.1)$ & $120(42.4)$ & $80(39.6)$ \\
\hline \multicolumn{6}{|l|}{ Toxicology analysis results, $\mathrm{n}(\%) \#$} \\
\hline $\begin{array}{l}\text { Concentration, } \mathrm{mg} / \mathrm{ml} \text {, median } \\
\text { (range) }\end{array}$ & $0.20(0.04-7.40)$ & $0.01(0.01-0.19)$ & $0.30(0.01-4.10)$ & $0.17(0.03-3.70)$ & $0.07(0.02-1.0)$ \\
\hline Supratherapeutic concentration & $40(2.7)$ & 0 & $274(57.6)$ & $77(27.2)$ & $126(62.4)$ \\
\hline No of substances, median(range) & $3(1-11)$ & $3(1-11)$ & $3(1-9)$ & $2(1-11)$ & $3(1-8)$ \\
\hline Scheduled drug & $1148(77.5)$ & $123(91.1)$ & $292(61.3)$ & $132(46.6)$ & $128(63.4)$ \\
\hline Illicit drug & $349(23.5)$ & $30(22.0)$ & $41(8.6)$ & $10(3.5)$ & $8(4.0)$ \\
\hline Opioid & $357(24.1)$ & 70 (51.9) & $69(14.5)$ & $64(22.6)$ & $59(29.2)$ \\
\hline Alcohol & $282(19.0)$ & $13(9.6)$ & $49(10.3)$ & $44(15.5)$ & $39(19.3)$ \\
\hline \multicolumn{6}{|l|}{ Dispensed prescription drugs, $\mathrm{n}(\%) \S$} \\
\hline Any drug & $1131(76.3)$ & $104(77.0)$ & $412(86.6)$ & $271(95.8)$ & $183(90.6)$ \\
\hline Any ATC $\mathrm{N}$ drug & $917(61.9)$ & $91(67.4)$ & $339(71.2)$ & $250(88.3)$ & $172(85.1)$ \\
\hline Any scheduled drug & $778(52.5)$ & $88(65.2)$ & $282(59.2)$ & $214(75.6)$ & $142(70.3)$ \\
\hline No of substances, median(range) & $4(1-35)$ & $4(1-32)$ & $5(1-33)$ & $9(1-64)$ & $8(1-30)$ \\
\hline
\end{tabular}

*DUID: driving under the influence of drug investigation 5 years preceding the arrest. **Highest attained educational level, individual disposable income and registered marital status for the calendar year of the DUID arrest. *** Low, middle and high income levels were defined as the 25, 25-75 and 75 percentiles for the Swedish general population aged $\geq 15$ years, in 2008 (Statistics Sweden, 2015). \#Forensic toxicologicy analysis of blood, part of a DUID investigation. Therapeutic levels of prescription drugs were defined based on the official list of the International Association of Forensic Toxicologists (TIAFT, 2010). Scheduled drugs were defined as drugs in classes II-V and illicit drugs as drugs in class I in Sweden (MPA, 2009). Opioids were defined as pharmaceutical drugs of Anatomical Therapeutic Classification (ATC) class N02A (WHO, 2008). § Dispenses of prescription drugs in Swedish outpatient pharmacies for the 365 days preceding the DUID arrest. 


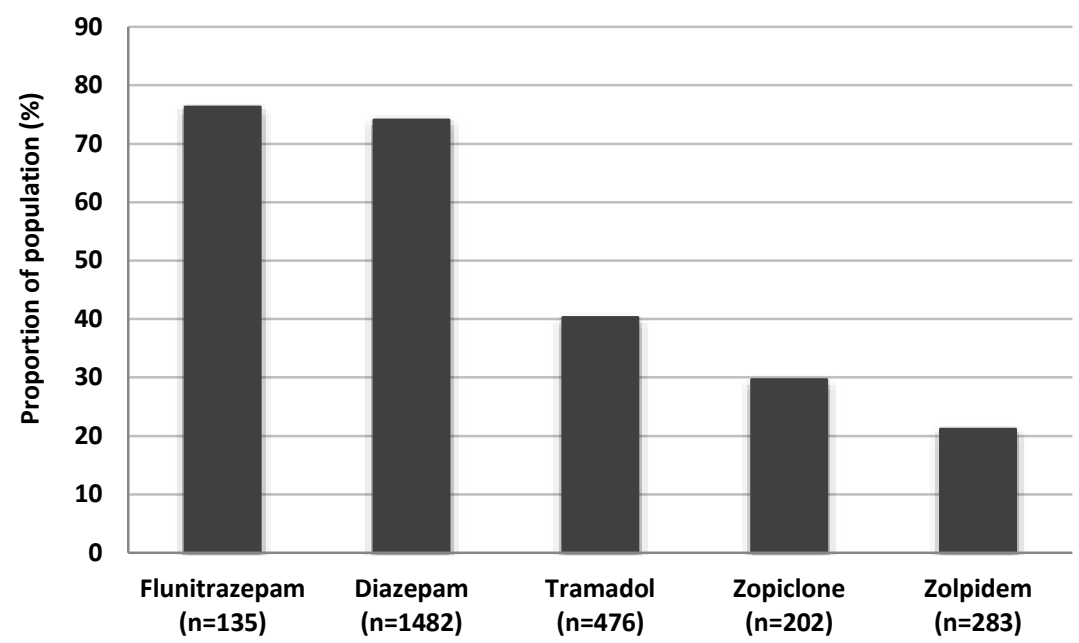

Fig. 1. 
Table 2. Factors associated with non-prescribed use of psychoactive prescription drugs in subjects suspected of drug-impaired driving $(\mathrm{N}=2225)$

\begin{tabular}{|c|c|c|c|c|c|c|c|c|c|c|}
\hline \multirow{2}{*}{$\begin{array}{l}\text { Variable } \\
\text { Adjusted ORs }\end{array}$} & \multicolumn{2}{|c|}{$\begin{array}{l}\text { Diazepam } \\
(\mathrm{N}=1479)\end{array}$} & \multicolumn{2}{|c|}{$\begin{array}{l}\text { Flunitrazepam } \\
(\mathrm{N}=135)\end{array}$} & \multicolumn{2}{|c|}{$\begin{array}{l}\text { Tramadol } \\
(\mathrm{N}=476)\end{array}$} & \multicolumn{2}{|c|}{$\begin{array}{l}\text { Zolpidem } \\
(\mathrm{N}=283)\end{array}$} & \multicolumn{2}{|c|}{$\begin{array}{l}\text { Zopiclone } \\
(\mathrm{N}=202)\end{array}$} \\
\hline & OR & (95\% Cls) & OR & (95\% Cls) & OR & (95\% Cls) & OR & (95\% Cls) & OR & (95\% Cls) \\
\hline \multicolumn{11}{|l|}{ Age group } \\
\hline $15-24$ years & 1.00 & (reference) & 1.00 & (reference) & 1.00 & (reference) & 1.00 & (reference) & 1.00 & (reference) \\
\hline $25-34$ years & 0.45 & $(0.27-0.74)$ & 0.48 & $(0.05-4.48)$ & 0.73 & $(0.41-1.30)$ & 0.49 & $(0.16-1.55)$ & 0.52 & $(0.13-2.10)$ \\
\hline $35-44$ years & 0.21 & $(0.12-0.35)$ & 0.13 & $(0.01-1.25)$ & 0.29 & $(0.15-0.57)$ & 0.38 & $(0.12-1.19)$ & 0.36 & $(0.09-1.36)$ \\
\hline $45-54$ years & 0.15 & $(0.08-0.27)$ & 0.26 & $(0.02-2.92)$ & 0.13 & $(0.05-0.34)$ & 0.21 & $(0.06-0.73)$ & 0.25 & $(0.06-1.05)$ \\
\hline$\geq 55$ years & 0.17 & $(0.07-0.41)$ & 0.03 & $(0.00-0.70)$ & 0.21 & $(0.05-0.82)$ & 0.16 & $(0.04-0.65)$ & 0.20 & $(0.03-1.28)$ \\
\hline \multicolumn{11}{|l|}{ Sex } \\
\hline Male & 1.00 & (reference) & 1.00 & (reference) & 1.00 & (reference) & 1.00 & (reference) & 1.00 & (reference) \\
\hline Female & 0.91 & $(0.60-1.37)$ & 2.21 & $(0.59-8.25)$ & 1.25 & $(0.61-2.55)$ & 0.77 & $(0.33-1.77)$ & 2.09 & $(0.77-5.67)$ \\
\hline $\begin{array}{l}\text { No of DUID } \\
\text { investigations }\end{array}$ & 0.85 & $(0.69-1.05)$ & - & - & 0.63 & $(0.43-0.92)$ & 0.52 & $(0.19-1.41)$ & - & - \\
\hline \multicolumn{11}{|l|}{ Education } \\
\hline Primary school & 1.00 & (reference) & 1.00 & (reference) & 1.00 & (reference) & 1.00 & (reference) & 1.00 & (reference) \\
\hline Secondary school & 0.86 & $(0.64-1.17)$ & - & - & 0.74 & $(0.45-1.19)$ & - & - & - & - \\
\hline $\begin{array}{l}\text { University or } \\
\text { College }\end{array}$ & 1.95 & $(1.00-3.83)$ & - & - & 2.28 & $(0.97-5.39)$ & - & - & - & - \\
\hline Income & - & - & - & - & - & - & - & - & - & - \\
\hline \multicolumn{11}{|l|}{ Marital status } \\
\hline Married, cohabite & 1.00 & (reference) & 1.00 & (reference) & 1.00 & (reference) & 1.00 & (reference) & 1.00 & (reference) \\
\hline $\begin{array}{l}\text { Unmarried, } \\
\text { divorced, } \\
\text { widow(er) }\end{array}$ & - & - & - & - & - & - & - & - & - & - \\
\hline \multicolumn{11}{|l|}{ Country of birth } \\
\hline Sweden & 1.00 & (reference) & 1.00 & (reference) & 1.00 & (reference) & 1.00 & (reference) & 1.00 & (reference) \\
\hline Other & - & - & - & - & - & - & - & - & - & - \\
\hline $\begin{array}{l}\text { Living in the region } \\
\text { of a large city }\end{array}$ & - & - & - & - & - & - & - & - & - & - \\
\hline \multicolumn{11}{|l|}{$\begin{array}{l}\text { Toxicology analysis } \\
\text { results }\end{array}$} \\
\hline $\begin{array}{l}\text { Conc. of drug, } \\
\mathrm{mg} / \mathrm{ml}\end{array}$ & - & - & - & - & - & - & - & - & - & - \\
\hline $\begin{array}{l}\text { Supratherapeutic } \\
\text { conc. of drug }\end{array}$ & - & - & - & - & - & - & - & - & - & - \\
\hline No of substances & 1.24 & $(1.06-1.44)$ & - & - & 1.36 & $(1.09-1.70)$ & - & - & - & - \\
\hline Scheduled drug & 1.73 & $(1.12-2.67)$ & - & - & 1.58 & $(0.86-2.93)$ & 2.76 & $(1.28-5.93)$ & 5.31 & $(1.73-16.27)$ \\
\hline Illicit drug & 0.63 & $(0.42-0.95)$ & - & - & - & - & 4.02 & $\begin{array}{l}(0.71- \\
22.87)\end{array}$ & - & - \\
\hline Opioid & - & - & - & - & - & - & - & - & - & - \\
\hline Alcohol & 0.74 & (0.51-1.09) & - & - & - & - & - & - & - & - \\
\hline \multicolumn{11}{|l|}{$\begin{array}{l}\text { Dispensed } \\
\text { prescription drugs }\end{array}$} \\
\hline No of drugs & 0.92 & $(0.88-0.95)$ & 1.03 & $(0.92-1.15)$ & 0.83 & $(0.78-0.89)$ & 0.94 & $(0.86-1.02)$ & 0.93 & $(0.84-1.03)$ \\
\hline Any ATC N drug & 0.17 & $(0.10-0.29)$ & 0.12 & $(0.01-1.05)$ & 0.43 & $(0.25-0.74)$ & 0.27 & $(0.10-0.74)$ & 0.03 & $(0.01-0.16)$ \\
\hline $\begin{array}{l}\text { Any scheduled } \\
\text { drug }\end{array}$ & 0.71 & $(0.63-0.80)$ & 0.69 & $(0.47-1.00)$ & - & - & 0.67 & $(0.47-0.94)$ & 0.61 & $(0.42-0.88)$ \\
\hline Intercept (p) & & $<0.0001$ & & 0.0008 & & 0.0263 & & 0.0195 & & 0.0005 \\
\hline Model chi $(p)$ & & $<0.0001$ & & $<0.0001$ & & $<0.0001$ & & $<0.0001$ & & $<0.0001$ \\
\hline $\begin{array}{l}\text { Model concordance } \\
(\%)\end{array}$ & & 86.7 & & 85.4 & & 82.5 & & 83.7 & & 88.3 \\
\hline
\end{tabular}

Results from a two-step logistic regression model. Variables with $p$-values $<0.25$ in the first step were included in the final model (figures shown). The response variable was non-prescribed use of the psychoactive prescription drug identified in blood upon DUID investigation. Non-prescribed use was defined as intake of the drugeonfirmed use (confirmed by toxicology analysis of blood) in a subject by whom it was not dispensed in the 12 month preceding the arrest. OR: Odds ratio. Cl: Confidence interval of the OR. Cls including the value 1.00 were not significant at the $p<0.05$ level. 


\section{Figure legends}

Fig 1: Prevalence of non-prescribed use among subjects suspected of drug-impaired driving with a confirmed intake of the psychoactive drugs flunitrazepam, diazepam, tramadol, zopiclone and/or zolpidem. The total number of subjects was 2225 . Non-prescribed use was defined as intake of the drug (confirmed by toxicological analysis in) a subject by whom it was not dispensed in the 12 month preceding the drug impaired driving arrest. The exact figures were as follows: flunitrazepam $76.3 \%$, diazepam $74.1 \%$, tramadol $40.3 \%$, zopiclone $29.7 \%$ and zolpidem $21.2 \%$. 